\title{
Implikatur Percakapan dalam Film Sweet 20 Karya Ody C. Harahap
}

\author{
Deby Prana Sari ${ }^{1}$, M. Syahrun Effendi* ${ }^{2}$ \\ Program Studi Pendidikan Bahasa dan Sastra Indonesia,STKIP PGRI Lubuklinggau ${ }^{1,2}$
}

Corresponding email: em.syahrun@yahoo.com*

\begin{abstract}
The purpose of this study was to describe the general conversational implicature, scale conversation implicature, and special conversation implicature in in the Sweet 20 film by Ody C. Harahap. The research method used is qualitative research methods. Data collection techniques used are documentation techniques and refer to techniques. Data analysis techniques by transcribing the entire contents of the film, marking implicature, interpreting, and making conclusions. Test the validity of the data with member checking and expert validity. From the results of the study, the dominant implicature used in the Sweet 20 film by Ody C. Harahap is a specific conversation implicator as much as $75 \%$, followed by a general conversation implicator as much as $21.33 \%$, and finally the scale implication as much as $3.79 \%$. The specific implications of the conversation in the form of using the language of speakers tend to use special words that only the speaker can understand the meaning or purpose of the speech. The Sweet 20 film is personal and familial in delivering speeches by speakers. From the results of this study, what needs to be considered is that when writing films Indonesian language teachers should pay attention to the composition of the use of implicature types.
\end{abstract}

Keywords: conversational implicature, film

\begin{abstract}
Abstrak
Penelitian ini bertujuan untuk mendeskripsikan implikatur percakapan umum, implikatur percakapan berskala, dan implikatur percakapan khusus dalam film Sweet 20 karya Ody C. Harahap. Metode penelitian yang digunakan yaitu metode penelitian kualitatif. Teknik pengumpulan data yang digunakan adalah teknik dokumentasi dan teknik simak. Teknik analisis data data dengan cara mentranskripsikan seluruh isi film, menandai implikatur, menginterpretasi, dan membuat kesimpulan. Uji keabsahan data dengan memberchek dan validitas pakar. Dari hasil penelitian, implikatur yang dominan digunakan dalam film Sweet 20 mentranskripsikan karya Ody C. Harahap yaitu implikatur percakapan khusus sebanyak $75 \%$, selanjutnya diikuti implikatur percakapan umum sebanyak $21,33 \%$, dan terakhir implikatur berskala sebanyak 3,79\%. Implikatur percakapan khusus berupa penggunaan bahasa penutur cenderung menggunakan kata-kata khusus yang hanya penuturlah yang bisa mengerti makna atau maksud tuturan tersebut. Film Sweet 20 ini bersifat pribadi dan kekeluargaan dalam menyampaikan tuturan oleh para penutur. Dari hasil penelitian ini, yang perlu
\end{abstract}


diperhatikan yaitu ketika menulis film hendaknya para guru bahasa Indonesia memperhatikan komposisi penggunaan jenis implikatur.

Kata kunci: implikatur percakapan, film

\section{PENDAHULUAN}

Karya sastra merupakan hasil kreativitas dan imajinasi pengarang dalam menceritakan suatu kehidupan masyarakat tertentu yang memiliki nilai dan manfaat (Redaksi, 2012:2; Noermanzah, 2017:27). Karya sastra juga merupakan huruf yang mengacu pada susunan kata dalam tata bahasa yang mengambarkan suatu peristiwa kehidupan (Rohman \& Emzir (2015:3). Effendi \& Hetilaniar (2019:63), menjelaskan bahwa karya sastra sebagai karangan yang menampilkan hasil kreativitas dari pengarang sehingga ada unsur fiksionalitas. Bentuk-bentuk karya sastra antara lain prosa, puisi, drama. Salah satu pengembangan dari drama yang bersifat dialog dan audiovisual yaitu dalam bentuk film (Noermanzah, 2012).

Film adalah media informasi yang dapat dilihat maupun didengar oleh pancaindra manusia (Murti dkk., 2018). Dalam hal ini, Trianton (2013:1) menjelaskan bahwa film adalah sebuah karya gambar yang bergerak, fungsinya sebagai sarana pendidikan yang menjadi pelajaran kehidupan. Selanjutnya, dalam film menurut Dewojati (2010:25) yaitu suatu adegan yang memperjelas secara negatif (kejahatan) dan positif (kebaikan) suatu tokoh yang dapat dilihat dari mata maupun suara. Senada dengan pendapat tersebut, Pratista (2008:1) mengemukakan bahwa film adalah pembentukan antara materi dan cara sutradara dalam berimajinasi di dalam karya yang telah dibuatnya melalui adegan per adegan yang diperankan oleh tokoh pilihan (artis) yang menurutnya cocok untuk berperan dalam filmnya. Seiring berjalannya waktu, film juga sering digunakan untuk media yang sangat mempengaruhi orang lain dalam bentindak dan berperilaku baik dalam bentuk ujaran maupun gerak. Bentuk ujaran inilah yang disebut dengan implikatur. Implikatur adalah maksud yang terkandung dalam sebuah ujaran.

Implikatur percakapan dapat terjadi dimana saja dan kapan saja, termasuk dalam sebuah film. Implikatur adalah salah satu bagian dari kajian pragmatik. Insan (2011:107) mengemukakan bahwa implikatur sebagai pesan yang terdapat pada ujaran lisan dan tulisan seseorang. Chaer (2010:33) mengemukakan bahwa implikatur adalah hubungan lisan seseorang dengan yang lainnya dalam komunikasi. Keterkaitan itu tidak tampak secara nyata, tetapi dapat dipahami secara tersirat. Mey (dalam Nadar, 2009:60) menjelaskan implikatur berasal dari kata kerja menyiratkan sedangkan kata bendanya implikasi. Sebuah film sangat menarik untuk diteliti karena dapat menguatkan maksud yang tersirat pada dialog percakapan antara tokoh yang ternyata ada di dalam kehidupan sehari-hari, khususnya dalam perencanaan untuk bertutur. Implikatur percakapan memiliki fungsinya sebagai sarana dalam bahasa komunikasi. Saputra (2015:91), menjelaskan bahwa implikatur percakapan memiliki fungsi yang dapat melancarkan komunikasi antara penutur dan lawan tutur (Syafryadin dkk., 2020). Dengan demikian, secara efektif pendengar dapat memberi respons atau tanggapan yang sesuai dengan implikatur yang muncul.

Penelitian tentang Implikatur percakapan dalam film ini pernah diteliti oleh Gulo \& Ritonga (2017) di Lapas Wanita Kelas II A Medan yang membahas tentang jenis-jenis implikatur percakapan umum, berskala, khusus, dan bagaimana makna implikatur dalam membangun percakapan yang terjadi di antara para penjaga dan 
tahanan di lapas. Selanjutnya, Yulianti (2008) meneliti implikatur dalam percakapan prinsip kerja sama dan implikatur pada tuturan alih kode dalam film-film Jerman. Selain itu, membahas tentang penaatan dan pelanggaran maksim-maksim percakapan yang menyangkut dengan implikatur percakapan umum dan implikatur percakapan khusus. Kurniati (2019) juga melakukan penelitian mengenai implikatur dan pelanggaran prinsip kerja sama dalam wacana percakapan debat calon Gubernur DKI Jakarta. Dalam penelitian ini bertujuan untuk mengetahui pelanggaran prinsip kerja sama, menganalisis fungsi implikatur, menganalisis jenis-jenis implikatur, dan menganalisis makna implikatur. Astuti (2017) melakukan penelitian mengenai implikatur percakapan dalam gelar wicara Sentilan Sentilun di Metro Tv. Dalam penelitian ini bertujuan untuk mendeskripsikan fungsi dan pelanggaran prinsip kerja sama/prinsip kesantunan dalam tayangan talk show (gelar wicara).

Dari beberapa hasil penelitian di atas, menunjukkan bahwa implikatur percakapan dalam film Sweet 20 karya Ody C. Harahap belum diteliti. Implikatur percakapan yang mengacu pada situasi isi film Sweet 20 Karya Ody C. Harahap ini memiliki beberapa bentuk, yaitu implikatur percakapan umum, berskala, dan khusus. Dalam penelitian ini peneliti menitikberatkan pada implikatur percakapan umum, implikatur percakapan berskala, dan implikatur percakapan khusus (Irma, 2019).

\section{METODE}

Metode yang digunakan dalam penelitian ini adalah metode penelitian kualitatif. Metode kualitatif ini digunakan bertujuan memberikan gambaran tentang karakteristik implikatur percakapan dalam film Sweet 20 karya Ody C. Harahap.. Teknik pengumpulan data yang digunakan adalah teknik dokumentasi dan teknik simak. Data dalam penelitian ini yaitu seluruh percakapan dalam film Sweet 20 karya Ody C. Harahap yang mengandung implikatur percakapan umum, implikatur percakapan berskala, dan implikatur percakapan khusus (Harahap, 2017).

Teknik analisis data dalam penelitian ini dengan langkah-langkah, yaitu mentranskripsikan seluruh isi film ke dalam bentuk tulisan, menandai implikatur percakapan yang ditemukan, menginterpretasi setiap temuan jenis implikatur percakapan, dan membuat kesimpulan hasil penelitian. Uji keabsahan data yang digunakan yaitu dengan memberchek dan validitas pakar sastra dan pakar pragmatik.

\section{HASIL}

Tuturan dalam film Sweet 20 karya Ody C. Harahap keseluruhan berjumlah 211 implikatur yang paling dominan adalah implikatur percakapan khusus sebanyak 158 tuturan (75\%), selanjutnya implikatur percakapan umum sebanyak 45 tuturan $(21,33 \%)$, dan yang terakhir implikatur percakapan berskala sebanyak 8 tuturan $(3,79 \%)$. Berikut adalah hasil penelitian dalam bentuk tuturan.

\section{Implikatur Percakapan Umum}

Berikut salah satu contoh kutipan percakapan dalam film Sweet 20 karya Ody

C. Harahap, dalam bentuk percakapan umum.

Fatma : Heck...heck, mau ngerasain tulang keropos? Ongkos dokter tanggung sendiri ya, sini! Apa lo. (langsung menarik Rahayu_dengan tangannya).

Rahayu : Eh, alisku, awas alisku.

Fatma : Alis gundul, bisa lihat tuyul. (Hamzah yang ada di sekitar mereka dan ingin memisahkan pertengkaran keduanya, akhirnya tangannya mengenai hidungnya 


\author{
Hamzah sehingga berdarah). \\ Rahayu : Hamski. (Durasi percakapan 05:17-05:39, (U06) Hal 337-338).
}

Pada tuturan di atas yang diujarkan Fatma kepada Rahayu untuk berkelahi, karena ucapan yang keluar dari bibirnya Rahayu membuat hatinya sangat panas apalagi tentang anak yang sangat ia cintai. Dalam tuturan ini mereka tidak ada satupun yang ingin mengalah, merasa paling benar, dan paling hebat dalam mendidik anak yang berujung perkelahian antara keduanya. Kutipan ke 60-63 dalam dialog, duduk bersama saat telah selesainya dansa. Pada tuturan ini mengandung makna implikatur percakapan umum. Bahwasanya Fatma merasa geram, lalu mengajak adu otot dan konteks percakapan "Ongkos dokter tanggung sendiri ya", ia tidak ingin bertanggung jawab atas terjadinya kerusakan wajah ataupun fisik pada Rahayu. Makna tersirat dari ucapan Rahayu ia malah ketakutan kalau sulam alisnya akan rusak karena tangannya Fatma. Makna dari ucapan Fatma yang terus emosi malah mengejek tentang alis yang palsu. Makna ucapan dari Rahayu dalam konteks percakapan "Hamski" itu nama panggilan khusus kepada Hamzah, dalam raut wajahnya Rahayu terdapat kekhawatiran yang mendalam ketika melihat hidung Hamzah bercucuran darah.

\title{
2. Implikatur Percakapan Berskala
}

Berikut salah satu contoh kutipan percakapan dalam film Sweet 20 karya Ody C. Harahap, dalam bentuk percakapan berskala.

Aditya : Bu maafin Adit, ya Bu. Kalau Adit banyak salah.

Fatma : Banyak salah gimana? Kamu tu anak ibu yang paling baik, pinter... sayang lagi sama ibunya. (Durasi Percakapan 01:04-01:09, (B01) Hal 335).

Tuturan yang disampaikan Aditya kepada Fatma di atas, menginformasikan bahwa ia ingin meminta maaf kepada ibunya karena merasa banyak sekali salah selama ini. Akan tetapi, ibunya menepis semua ucapan anaknya dan merasa Aditya tidak ada salah. Justru ia dikenal oleh ibunya anak yang penurut sama orang tua, berperilaku baik, dan sempurna di mata ibunya. Dalam hal ini, Aditya sedang mengoreksi dirinya sendiri dan Aditya mencoba meminta maaf. Kemudian, kutipan ke 13-14 dalam dialog, terjadi pada saat hari raya Idul Fitri, di meja makan, berupa implikatur berskala yang terdapat dalam dialog ini yang mempunyai makna tersirat dari tuturan Aditya dalam konteks percakapan "banyak salah" kepada orang tuanya entah itu berupa perlakuan yang kurang sopan, melawan kepada orang tua, dan kata-kata yang menyinggung hati orang tua, untuk bisa dimaafkan oleh ibunya. Makna tersirat dalam tuturan Fatma yang menyangkal tentang banyaknya salah yang telah diperbuat anaknya, karena di matanya Aditya anak yang baik.

\section{Implikatur Percakapan Khusus}

Berikut salah satu contoh kutipan percakapan dalam film Sweet 20 karya Ody

C. Harahap, dalam bentuk percakapan khusus.

$\begin{array}{ll}\text { Fatma } & \text { :Adit tunggu! } \\ \text { Aditya } & : \text { Iya Bu. } \\ \text { Fatma } & : \text { Ini, ibu bawain bekal makan siang. } \\ \text { Aditya } & \text { : Makasih ya bu. } \\ \text { Fatma } & \text { : He,eh (lya). } \\ \text { Aditya } & : \text { Aku berangkat dulu ya, Bu. }\end{array}$


Fatma : He, eh... hati-hati di jalan pak dosen.

Aditya : lya bu (sambil membukakan pintu mobil).

Salma : Hati-hati ya.

Fatma : Kamu tuh ya, suami kerja keras setiap hari, apa salahnya siapin dia makan siang?

Salma : Hanya diam saja.

(Durasi Percakapan 07:21-07:45, (K17) Hal 339).

Tuturan Fatma kepada Aditya dalam kutipan percakapan di atas membuktikan bahwa ia senang sekali melihat anaknya menjadi dosen, dan ia selalu memberi perhatian kepada anaknya bahkan membuat sarapan pagi untuk anaknya. Secara khusus memberi perhatian untuk anaknya yang ingin berangkat bekerja mencari sesuap nasi untuk ibu, istri, dan anak-anaknya yang ada di rumah. Kemudian, sebagai seorang istri yang baik, hendaknya menyiapkan makan siang untuk suami yang sudah letih dalam mencari nafkah untuk keluarganya. Kutipan ke 85-95 dalam dialog, saat di rumahnya Fatma, Aditya ingin cepat-cepat berangkat ke kantor. Implikatur khusus yang terdapat dalam dialog mempunyai makna tersirat dari tuturan Fatma yang ingin menghentikan langkah kakinya Adit. Makna tersirat dari tuturan Aditya yang bersedia menunggu ibunya. Makna tersirat dari ucapan Fatma yang ingin memberikan bekal untuk anak kesayangannya agar tidak kelaparan. Makna tersirat dari ucapan Adit senang menerima pemberian dari ibunya. Makna dari ucapan Fatma tentu saja ikut senang. Makna tersirat yang dituturkan oleh Aditya yang meminta izin dengan orang tuanya untuk mencari sesuap nasi. Makna tersirat dari tuturan Fatma memberi izin dan doa kepada anaknya. Makna tersirat ucapan Salma yang mengharapkan suaminya baik-baik saja saat sedang menyetir. Makna tersirat dari ucapan Fatma yang kesal karena tidak pernah ingin memberi bekal kepada suaminya sendiri yang sudah berusaha keras untuk menafkahi keluarga. Sedangkan, makna tersirat dari ekspresif yang ada di dalam wajahnya Salma merasa bersalah dan tertekan dengan perkataan dari lbu mertuanya.

\section{PEMBAHASAN}

Implikatur percakapan dalam film Sweet 20 karya Ody C. Harahap memiliki variasi implikatur, tetapi yang paling dominan digunakan yaitu implikatur percakapan khusus. Implikatur yang dibangun oleh penulis naskah film atau penulis karya sastra yang lainnya yaitu ingin membangun komunikasi antar tokoh sehingga menimbulkan konflik kehidupan yang perlu diselesaikan (denouement) dengan cara yang dramatis (Noermanzah, 2017:33). Semakin dramatis percakapan yang diujarkan maka akan semakin menarik film tersebut.

Karya sastra merupakan hasil kreativitas dan imajinasi pengarang sebagai salah satu bentuk karya seni yang dijadikan alat untuk menuangkan ekspresi, ide, dan gagasan pengarang yang terdapat di dalamnya yang berisi pesan kehidupan (Redaksi, 2012:2). Karya sastra adalah salah satu sumber dari ide pemikiran dari penulis yang menggambarkan pengalaman kehidupannya sendiri atau orang lain dan kehidupan di lingkungan sekitarnya. Pengalaman bisa diperoleh dari menyimak dari cerita atau kejadian yang dialami orang lain, mengamati keadaan lingkungan sekitar, menonton televisi, pengalaman sendiri, keluarga, teman, dan sebagainya. Hasil dari pengalaman tersebut dapat dijadikan pedoman maupun ide baru berupa imajinasi, sehingga lahirlah sebuah karya yang layak untuk diperlihatkan melalui media gerak, suara, dan gambar untuk semua orang. 
Implikatur percakapan dari film Sweet 20 karya Ody C. Harahap berisi pengalaman hidup yang dialami penulis atau ide hasil pemikiran penulis dituangkan dalam film Sweet 20. Permasalahan kehidupan pribadi, kekeluargaan, sosial, serta kehidupan masyarakat yang berkaitan dengan perjalanan hidup orang lain. Hal ini menjadi bahan cerita yang dijadikan gagasan atau ide pemikiran dalam bentuk imajinasi ke dalam film Sweet 20. Permasalahan kekeluarga dan bersifat pribadi, pengorbanan seorang nenek untuk kebahagiaan keluarganya.

Implikatur adalah salah satu bagian dari kajian pragmatik, yang mengkaitkan tentang bahasa di dalamnya melalui tuturan dan lawan tuturnya. Implikatur adalah pesan yang terdapat pada ujaran lisan dan tulisan seseorang yang akan disampaikan secara sepontan (Ihsan, 2011:107). Implikatur adalah hubungan lisan seseorang dengan yang lainnya dalam bahasa komunikasi (Chaer, 2010:33). Pengarang, dalam film Sweet 20 jelas akan memberi banyaknya pembelajaran tentang kekeluargaan yang harus lebih menghormati orang tua kita walaupun ia sangat cerewet. Kemudian, kebanyakan anak-anak memang tidak tahan dengan sikap orang tuanya yang selalu saja mengatur kehidupan pribadi anaknya dari kecil hingga ada juga yang sudah menikah masih diatur oleh orang tuanya. Dalam hal ini, pengarang menuliskan karyanya dengan melihat situasi sekitar yang sering terjadi di kalangan masa dulu maupun sekarang dari sebuah pengalaman. Gambaran kehidupan dari pengalaman sendiri, keluarga, dan teman yang ada dalam cerita film Sweet 20 karya Ody C.Harahap telah menyampaikan inspirasi kepada penonton tentang cara menghormati, memahami, menghargai orang tua secara benar kepada orang-orang yang belum mengerti cara menghargai pendapat dan kasih sayang orang tua kepada mereka. Sebagai seorang anak kita semua wajib memahami sifat, watak, tingkah laku, dan cara orang tua memberi kasih sayang melalui tuturan yang disalahartikan oleh kebanyakan orang.

Faedah implikatur yang dapat dipetik dari sini yaitu, memberi bentuk penjelasan dengan tepat tentang perbedaan dari si pemakai bahasa itu sendiri, memberi fakta dari berbahasa, penjelasan pemberian ilmu bahasa yang sederhana, memberi bentuk berbagai kebenaran yang secara tumbuhnya langsung kelihatan tidak adanya kaitan, malah menjadi lawannya. Hal ini sesuai dengan pendapat Levinson (dalam Lubis, 2011:73) bahwa film ini memiliki faedah yang berupa fakta dan terjadi dalam kehidupan orang lain, dalam film ini memiliki ilmu kesopanan terhadap orang tua dan orang tua juga seharusnya janganlah egois dan selalu menginginkan apa yang tidak dihendaki oleh anaknya. Secara bertutur haruslah saling menghargai orang yang ingin mengeluarkan pendapatnya masing-masing dan kalau semua itu terjadi ia tidak akan menyinggung satu sama lain.

Pengarang mengangkat jenis implikatur percakapan umum tidak ada latar belakang yang khusus dalam konteks yang diminta hanya membuat kesimpulan saja. Implikatur berskala menyatakan suatu nilai dari suatu skala nilai. Sebagian selalu, kadang-kadang, banyak, beberapa, dan ketika sedang bertutur. Implikatur percakapan khusus menyesuaikan konteks sangat khusus di mana kita memberikan pendapat mengenai informasi yang kita ketahui secara lokal (Yule, 2006:70). Berdasarkan penggunaan bahasa penutur dalam film Sweet 20, cenderung menggunakan kata-kata khusus yang hanya penuturlah yang bisa mengerti makna atau maksud tuturan tersebut.

Pemikiran negatif tentang film yaitu ada nilai-nilai negatif yang terkadang susah diterjemahkan oleh penonton sebagai nilai positif, memiliki biaya produksi tinggi, memperoses membutuhkan waktu, tidak bisa langsung, sering kali tidak 
memiliki sarana produksi film, film yang sudah dipakai tidak dapat dihapus dan digunakan kembali, harus dirawat, dan ditangani dengan hati-hati agar tidak mudah rusak (Prastowo, 2011:309-310). Dalam film Sweet 20 ini memiliki pemikiran negatif tentang anak, menantu, cucu kepada neneknya yang cenderung ingin mengatur segala kehidupan di rumah tangganya. Kita bisa membayangkan kalau nenek berbicara beberapa kalimat untuk kesehatan, agar tidak memakai gula putih yang seharusnya memakai gula merah dianggap cerewet padahal semuanya untuk kesehatan semata. Neneknya menyuruh memakai pakaian tertutup saat Lebaran dianggap cucunya cerewet padahal untuk kebaikan dan keanggunan cucunya, Neneknya menyuruh membuatkan bekal untuk suaminya karena telah bekerja seharian dianggap mengatur rumah tangga anaknya. Semua hal yang dikatakan oleh tokoh Fatma sangat membantu kelangsungan hidup agar tetap sehat. Oleh karena itu, orang tua haruslah memberikan pemahaman yang lebih lembut agar menantu, cucu tidak salah paham dengan keadaan.

Pengarang, yakni Ody C. Harahap dalam filmnya Sweet 20 menghadirkan 38 pemain film. Tokoh Fatmawati (tua) yang telah menjadi Mieke (muda) di sini menjadi peran utama yang sangat berperan penting atas semua kejadian. Problematika ini terjadi karena kecerewetan Fatma terhadap menantu dan cucu perempuannya yang bernama Luna yang tidak penurut seperti Juna. Hingga suatu hari dia tahu bahwa dirinya akan dikirim ke panti jompo karena usulan dari Luna yang tidak menyukai kehadiran neneknya di dalam rumah. Luna merasa kalau Fatma pilih kasih kepada dia, tetapi kalau dengan Juna sangat dimanjakan Fatma, dan Luna merasa kalau Ibunya Salmah sakit pasti gara-gara sering dimarah oleh Neneknya. Hal tersebut membuat dirinya menjadi sangat sedih dan pergi dari rumah.

Saat perjalanan, dia melihat studio foto yang bernama "Forever Young" yang artinya selamanya muda. Di sana dia berfoto yang dimaksudnya untuk foto pemakamannya kelak. Namun, hal ajaib terjadi kepadanya. Setelah berfoto dirinya berubah menjadi seorang wanita muda yang sangat cantik berusia 20 tahun seumur dengan cucunya dan dia juga mengganti namanya menjadi Mieke Wijaya seperti artis idolanya. Semenjak itulah Fatmawati memulai kehidupan barunya dengan mengejar cita-citanya yang dulu ingin sekali menjadi penyanyi dan sempat tertunda saat dia muda.

Selain itu, melalui tokoh-tokoh yang dibuat pengarang, tokoh utama dan keluarga sempat terpisah karena ketidaktahuan keluarga bahwa Fatma berusia 70 tahun telah menjadi wanita cantik yang berumur 20 tahun. Mereka sering bertemu namun Aditya, Salma, Juna, Luna, Hamzah dan yang lain tidak mengenali rupa dari wajah Fatma dan tidak terpikirkan kalau itu adalah Fatma yang berusia 70 tahun. Suatu peristiwa terjadi, yang membuat Mieke harus memilih untuk melanjutkan kehidupan barunya tetap muda tanpa menolong cucunya Juna yang sedang kritis di rumah sakit sedang banyak kehilangan darah karena kecelakaan, atau kembali menjadi Fatmawati yang tentu saja hilang wajah cantiknya dan impiannya.

Tuturan percakapan di film Sweet 20 karya Ody C. Harahap ditemukan 211 implikatur dengan variasi implikatur percakapan. Implikatur yang paling dominan adalah implikatur percakapan khusus 158 tuturan (75\%), selanjutnya implikatur percakapan umum sebanyak 45 tuturan $(21,33 \%)$, dan yang terakhir implikatur percakapan berskala 8 tuturan $(3,79 \%)$. Dari persentase penggunaan jenis implikatur ini dapat dijadikan model bagi guru bahasa Indonesia ketika mengajarkan menulis naskah film. 


\section{KESIMPULAN DAN SARAN}

Film Sweet 20 karya Ody. C. Harahap menggunakan variasi impikatur. Implikatur yang paling dominan yaitu implikatur percakapan khusus sebanyak 158 tuturan (75\%). Kemudian, terdapat juga implikatur percakapan umum sebanyak 45 tuturan $(21,33 \%)$, dan implikatur yang paling rendah ialah implikatur berskala sebanyak 8 tuturan $(3,79 \%)$. Dominasi penggunaan implikatur percakapan khusus disebabkan karena topik pembicaraan yang dituturkan hanya lawan tuturlah yang bisa memahami maksud yang dituturkan. Film ini bersifat pribadi dan kekeluargaan dalam menyampaikan tuturan.

Berkaitan dengan Pendidikan Bahasa dan Sastra Indonesia melalui pengajaran sastra, khususnya bagi pembaca, hasil penelitian ini dapat digunakan dengan baik sebagai sumber informasi atau pengetahuan mengenai impikatur percakapan dalam kehidupan sehari-hari sehingga diharapkan pembaca paham dan mengerti mengenai implikatur. Pembelajaran sastra, penelitian ini dapat dijadikan salah satu bahan ajar tentang memahami cara menulis film dengan variasi implikatur. Film ini dapat dijadikan sumber ilmu yang bermanfaat bagi kita semua, dan hasil penelitian dari penulis juga bisa bermanfaat sebagai penelitian lanjutan dalam mengkaji implikatur dalam suatu film.

\section{DAFTAR PUSTAKA}

Astuti, W. D. (2017). Implikatur Percakapan dalam Gelar Wicara "Sentilan Sentilun" di Metro TV. Kandai, 13(2), 311. doi:10.26499/jk.v13i2.306

Chaer, A. (2010). Kesantunan Berbahasa. Jakarta: PT Rineka Cipta.

Dewojati, C. (2010). Drama Sejarah, Teori, dan Penerapannya. Yogyakarta: Gadjah Mada University Press.

Effendi, D., \& Hetilaniar, H. (2019). Pandangan Dunia Pengarang dalam Novel Bulan Terbelah di Langit Amerika Karya Hanum Salsabiela Rais dan Rangga Almahendra serta Implikasinya dalam Pengajaran Sastra. Diksa: Pendidikan Bahasa Dan Sastra Indonesia, 5(2), 63. doi:10.33369/diksa.v5i2.9707

Gulo, M. I. \& Ritonga, M. U. (2017). Implikatur Percakapan di Lapas Wanita Kelas II A Medan. Medan (3). Kode: Jurnal Bahasa, 6(4). https://jurnal.unimed.ac.id/2012/index.php/kjb/article/view/10838

Harahap, Ody C. (2017). Sweet 20 (DVD Original). CJ Entertainment.

Ihsan, D. (2011). Pragmatik, Analisis Wacana, dan Guru Bahasa. Palembang: Universitas Sriwijaya.

Irma, C. N. (2019). Analisis Fungsi dan Bentuk Implikatur dalam Iklan Sprite: Kenyataan yang Menyegarkan di Televisi. Jurnal Hasta Wiyata, 2(2), https://hastawiyata.ub.ac.id/index.php/hastawiyata/article/view/34 
Kurniati, A. (2019). Implikatur dan Pelanggaran Prinsip Kerjasama dalam Wacana Percakapan Debat Calon Gubernur DKI Jakarta (Penelitian Analisis Isi dalam Acara Gelar Mata Najwa di Metro TV). Deiksis : Jurnal Pendidikan Bahasa dan Sastra Indonesia, 6(1), 91. doi:10.33603/deiksis.v6i1.1215

Lubis, H. H. (2011). Analisis Wacana Pragmatik. Bandung: Angkasa Bandung.

Murti, S., Nisai Muslihah, N., \& Permata Sari, I. (2018). Tindak Tutur Ekspresif dalam Film Kehormatan di Balik Kerudung Sutradara Tya Subiakto Satrio. Silampari Bisa: Jurnal Penelitian Pendidikan Bahasa Indonesia, Daerah, Dan Asing, 1(1), 17-32. doi:10.31540/silamparibisa.v1i1.7

Nadar, FX. (2009). Pragmatik \& Penelitian Pragmatik. Yogyakarta: Graha Ilmu.

Noermanzah, N. (2012). Figurative Language dalam Wacana Drama Seri "Upin dan Ipin" Karya Simon Monjack dengan Tinjauan Deskriptif. Jurnal Perspektif Pendidikan, 5(1), 11-23, https://ojs.stkippgrilubuklinggau.ac.id/index.php/JPP/article/view/347

Noermanzah, N. (2017). Plot in a Collection of Short Stories "Sakinah Bersamamu" Works of Asma Nadia with Feminimism Analysis. Humanus, 16(1), 27. doi:10.24036/jh.v16i1.7015

Prastowo, A. (2011). Panduan Kreatif Membuat Bahan Ajar Inovatif. Jogjakarta: Diva Press.

Pratista, H. (2008). Memahami Film. Yogyakarta: Homerian Pustaka.

Redaksi PM. (2012). Sastra Indonesia Paling Lengkap. Jawa Barat: Pustaka Makmur.

Rohman, S. \& Emzir. (2015). Teori dan Pengajaran Sastra. Jakarta: PT RajaGrafindo Persada.

Saputra, Mujiyono, Akhyarudin. (2015). Implikatur Percakapan dalam Stand Up Comedy Indonesia di Stasiun Kompas TV Edisi April 2014. Pena, 5(1), https://online-journal.unja.ac.id/pena/article/view/4349

Syafryadin, Dian, E. C. Wardhana., Eka Apriani., \& Noermanzah. (2020). Maxim Variation, Conventional, and Particularized Implicature on Students' Conversation. International Journal of Scientific and Technology Research, 9(2) https://doi.org/10.31219/osf.io/cza8y.

Trianton, T. (2013). Film sebagai Media Belajar. Yogyakarta: Graha Ilmu.

Yule, G. (2006). Pragmatik. Yogyakarta: Pusaka Pelajar.

Yulianti, A. A. (2018). Prinsip Kerja Sama dan Implikatur pada Tuturan Alih Kode dalam Film-Film Jerman. Belajar Bahasa, 3(2). doi:10.32528/bb.v3i2.1582 